\title{
Tratado de Imágenes (for trio and video track)
}

\author{
Iñigo Giner Miranda \\ Composer \\ Köpenicker Straße 10110179 Berlin, Germany \\ i.ginermiranda@gmail.com
}

Audiovision. Musiktheater. Live music. 1920s. 1930s.. Experimental films. Synchrony.

\begin{abstract}
"Tratado de imágenes" ("Image treaty") - 2009 - is a piece for live trio - violin, clarinet, piano - and video track. It is a practical research on the possible relationships between sound and image, explored from a joint approach: sound was not considered to be something external to the image, nor was image complementary to the sound. The artistic intention behind this work is for both images and sounds to build the musical context together, instead of thinking one of them purely as a translation (or embellishment) of the other. Synchrony is therefore used exhaustively in the piece, as it is a powerful means of uniting the different media.
\end{abstract}

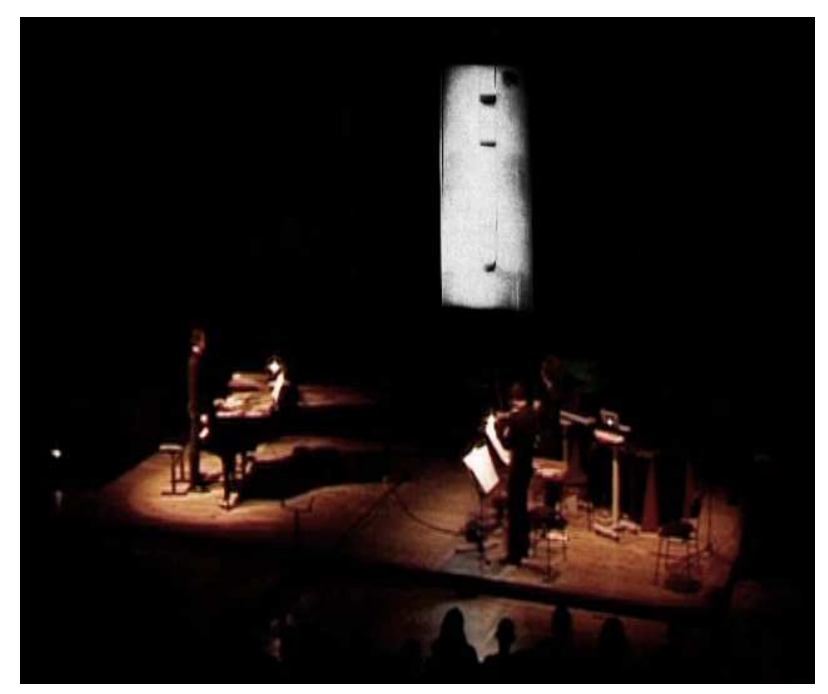

This type of relation called for a composition process which would allow the composer to have a complete overview of all materials, and not just the sounding materials and a vague impression of the visual elements. The video track of the piece was therefore also prepared by the composer, comprising a series of excerpts from experimental 1920s-30s videos (La retour a la raison - Man Ray, Ballet mécanique - Ferdinand Leger, and Regen - Joris Ivens) as well as original images. All images either are or verge on the abstract, and thus favour a relationship with the music built on equal terms, where the visual can behave "musically", so to speak. At the same time the images used all present a different inner grammar, so to speak, that favours certain relations with the music, while hindering others. Thus, while the general relation of synchrony remains more or less unaffected for the whole piece, the actual relationships between both media vary according to the context proposed by both sounds and the image in every section.

The musicians, in this context of cross relations, are also considered as image, a thought that is exploited at different points in the piece, by either engaging them in silent passages (where we see a ballet of musical gestures that do not yield any sound) or having them perform actions that cross over into the theatrical, in a way that recontextualizes their relation to the video. 